\title{
MANEJ O MÉDICO DEL ONFALOCELE GIGANTE CON SULFADIAZINA DE PLATA TÓPICA
}

J hon Camacho M D*, Hector Romero M D**, N estor M uñetones M D***, Sandra Navarro M D***

\section{Resumen}

El onfalocele es un defecto congénito de la pared abdominal, de presentación infrecuente, que puede asociarse con otro tipo de malformaciones genéticas. El manejo es quirúrgico y consiste en la reducción de las vísceras herniadas para cerrar la fascia y la piel, aunque el onfalocele gigante representa un problema mayor debido al tamaño del defecto, por lo cual el cierre primario con frecuencia debe diferirse. Se presenta un recién nacido con diagnóstico prenatal de onfalocele gigante a quien se realiza manejo médico con sulfadiazina de plata para epitelizar el saco con adecuado éxito, logrando diferir el manejo quirúrgico.

Palabras clave: onfalocele gigante, manejo médico, sulfadiazina de plata.

Abreviaturas: OG, onfalocele (s) gigante (s).

\section{INITIAL NONOPERATIVE MANAGEMENT OF GIANT OMPHALOCELE USING TOPICAL SILVER SULFADIAZINE}

\section{Abstract}

Omphalocele is a rare birth defect of the abdominal wall which may be associated to other genetic abnormalities. It is managed surgically by reducing the herniated organs followed by closure of the fascia and skin. However, giant omphalocele represents a greater problem due to the size of the defect, for which the final closure must be delayed. We present an infant with a prenatal diagnosis of giant omphalocele initially treated with silver sulfadiazine coverage allowing epithelialization of the sac constituting a bridge to delayed surgical closure.

Key words: giant omphalocele, medical management, silver sulfadiazine

Fecha recibido: mayo 16 de 2014 - Fecha aceptado: octubre 26 de 2014

* Médico pediatra, Hospital de San José. Bogotá DC. Colombia.

* Médico pediatra, epidemiólogo, Instructor Asistente, Fundación

Universitaria de Ciencias de la Salud. Bogotá DC. Colombia.
*** Médico pediatra, neonatólogo, Instructor Asistente, Fundación Universitaria de Ciencias de la Salud. Bogotá DC. Colombia. 


\section{Introducción}

El onfalocele, del griego "omphalos = ombligo y kele $=$ hernia o tumor" ${ }^{1}$, es un defecto ventral de la pared abdominal donde las vísceras del contenido herniario están cubiertas por una membrana. El llamado gigante es aquel que mide más de $5 \mathrm{~cm}$ y que contiene más del $75 \%$ del hígado en el defecto. ${ }^{2} \mathrm{El}$ objetivo del manejo quirúrgico es la reducción de las vísceras herniadas, el cierre de la fascia y la piel para reparar la integridad de la pared abdominal. Los pacientes con OG representan un reto terapéutico y su manejo es controvertido debido a que estos ameritan ciertas medidas para epitelizar la membrana antes de optar por el manejo quirúrgico definitivo, el cual a menudo debe ser diferido. ${ }^{3} \mathrm{La}$ sulfadiazina de plata se ha propuesto como una medida médica para promover la epitelización con resultados seguros y efectivos. ${ }^{4}$

\section{Reporte de caso}

Recién nacido masculino a término, de 38 semanas por Ballard, con peso adecuado para la edad gestacional, nace por cesárea fruto de la primera gestación con diagnóstico prenatal de OG por ecografía, cuyas imágenes sugieren hígado en saco herniario. Nace vigoroso con APGAR (6-8-10), requiere ventilación con presión positiva por apnea secundaria, aunque después presenta dificultad respiratoria por lo cual se decide intubación orotraqueal. Al examen físico se evidencia abdomen excavado con OG, saco íntegro, de cerca de $20 \mathrm{~cm}$ de diámetro, contiene vísceras sólidas y huecas en su interior (Figura 1). Se evidenció criptorquidia bilateral. Por el tamaño del defecto abdominal se cubren las vísceras con bolsa de polivinilcloruro (viaflex), se avanza sonda orogástrica y se traslada a unidad de recién nacidos.

Durante la evolución acoplado a ventilación mecánica se inicia nutrición parenteral total. El perfil de infección inicial fue negativo, el ecocardiograma a las 48 horas de vida revela ductus arterioso persistente pequeño sin repercusión hemodinámica, la ecografía de abdomen no logra visualizar el hígado y el resto de órganos incluido páncreas y riñones fueron normales.

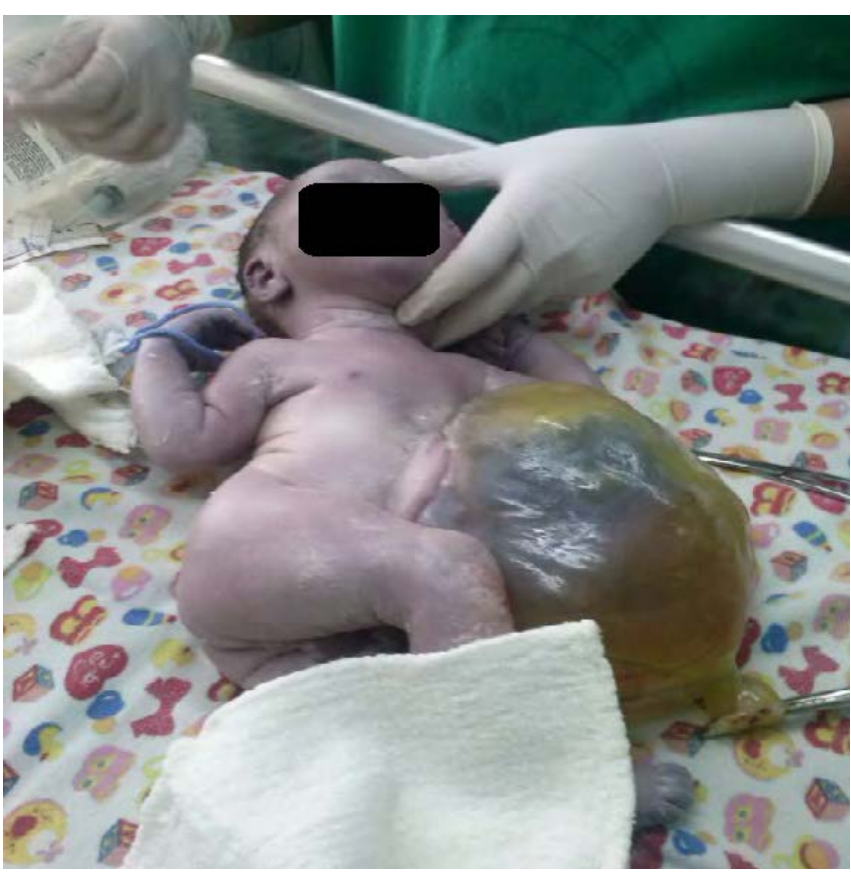

Figura I. Onfalocele gigante en periodo neonatal inmediato.

Valorado por cirugía pediátrica consideran que debido al defecto abdominal severo no hay posibilidad inmediata de corrección quirúrgica, por lo que el manejo será expectante. Deciden iniciar pincelaciones de mercurio cromo, toques diarios por tres días y luego cada tres días, para contribuir a la formación de costra, buscando mejorar las condiciones de la membrana para después realizar corrección quirúrgica. El hemograma y la proteína $\mathrm{C}$ reactiva (PCR) de control a las 48 horas de vida fueron en ascenso $(4,8 \mathrm{mg} / \mathrm{dL})$ y ante la sospecha de sepsis neonatal temprana se inició ampicilina y amikacina. Al quinto día de vida se logró la extubación y el paso a ventilación mecánica no invasiva tipo nasal con adecuado éxito. Se pasó a oxígeno por cánula de alto flujo y al octavo día de vida presentó dos deposiciones. En conjunto con cirugía pediátrica se inició vía enteral trófica. Al siguiente día presentó aumento de requerimientos de oxígeno, dificultad respiratoria, PCR aumentada (38 mg/dL) y en la radiografía se detectó proceso neumónico basal derecho. Se decide iniciar cefepime, vancomicina y toma de policultivos, así como suspensión de vía enteral por vómito en tres oportunidades. Valorado por genética consideran riesgo bajo de cromosomopatía por tratarse de onfalocele gigante, pero sugieren estudio de cariotipo bandas G. 
A los 14 días de vida la evolución clínica es estable, los hemocultivos son negativos y la PCR en descenso. La junta médica interdisciplinaria de neonatología, cirugía pediátrica y medicina materno fetal considera el onfalocele gigante con bajo riesgo de asociación y por riesgo de toxicidad con mercurio cromo se decide iniciar sulfadiazina de plata. Presentó pico febril y crecimiento de K lebsiella pneumoniae BLEE positiva en líquido peritoneal por lo cual se inició meropenem. La epitelización de membrana sobre el onfalocele fue adecuada, sin pus, asas intestinales rosadas y en buen estado. El paciente cursó con evolución favorable a nivel de cubierta de onfalocele y se logró adecuada epitelización del tejido con sulfadiazina de plata (Figura 2). Hay buena ganancia de peso y tolera la nutrición enteral. Durante el tratamiento no se reportaron reacciones adversas al uso de sulfadiazina de plata.

\section{Disc usión}

El onfalocele es un defecto congénito centrado de la pared abdominal, con herniación del contenido, por lo regular intestino, hígado u otros órganos. Además está cubierto por una membrana de peritoneo, gelatina de Wharton, amnios y los vasos umbilicales se insertan en esta y no en la pared abdominal. ${ }^{1,4}$ Es una patología infrecuente que causa importante morbimortalidad. La epidemiologia varía de acuerdo con la población estudiada, su prevalencia calculada es de 1 por cada 10.000 nacimientos en países occidentales ${ }^{1}$, la incidencia varía entre 1,5 a 3 por 10.000 nacimientos $^{3}$ y en Colombia se desconoce su prevalencia. Existe un ligero predominio del sexo masculino, cerca de 1.5 a 3 hombres por cada mujer. ${ }^{5}$ Se asocia con frecuencia con otras anormalidades en 50 a 70\%, frente a las gastrosquisis donde las anormalidades son más raras. ${ }^{6}$ Entre las más comunes se han reportado cardiopatías congénitas, malformaciones renales, genitourinarias, faciales, esqueléticas y gastrointestinales. Además hay anomalías cromosómicas en 8 a $40 \%$ de los casos, como la trisomia 13 y 18 , y con menos frecuencia trisomias $14,15,16,17$ y $21^{5,6}$ (Tabla 1). Existe una relación entre el tamaño del defecto y el riesgo de cromosomopatía, en general los gigantes tienen baja posibilidad y viceversa. ${ }^{5} \mathrm{La}$ infección, el ileo, la enterocolitis necrosante son causas importantes de morbilidad. La sobrevida en casos de onfaloceles aislados varía entre 75 y $95 \%$. La mortalidad depende de los defectos asociados, en especial cardiopatía y cromosomopatías, pero se calcula entre $25 \%$ y $80 \% .^{5}$

En condiciones normales la pared abdominal se forma por la invaginación de cuatro pliegues somáticos, uno cefálico, dos laterales y otro caudal, en la cuarta semana de gestación. Cerca de la sexta semana hay un crecimiento intestinal rápido, aunque el hígado y los riñones ocupan la mayor parte de la cavidad abdominal, así que el espacio es limitado para el crecimiento

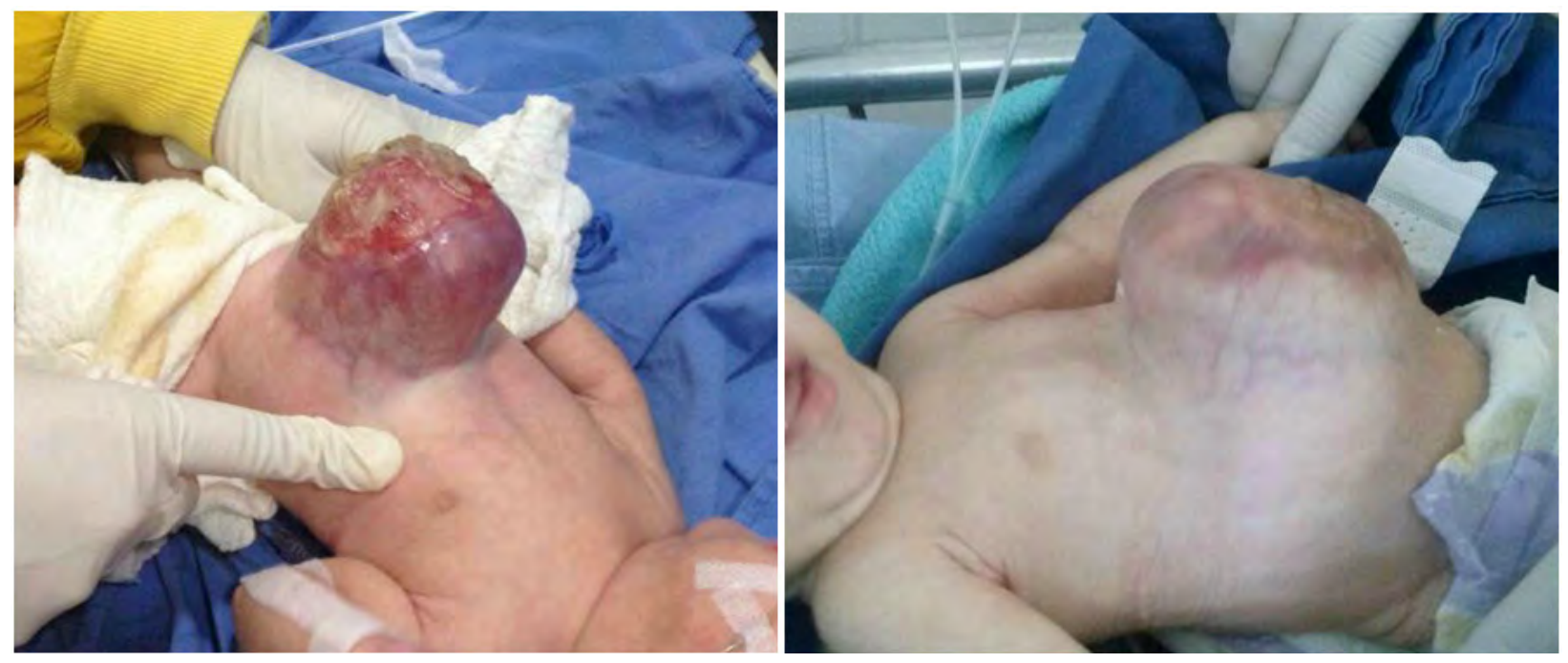

Figura 2. Evolución del onfalocele gigante a los 50 días de vida. 


\begin{tabular}{|c|c|c|}
\hline Anormalidad & Incidencia & Frecuencia \\
\hline Cromosómica & $30-40 \%$ & $\begin{array}{l}\text { Trisomia } 13 \text { y } 18 \\
\text { Síndrome de Beckwith-Wiedemann }\end{array}$ \\
\hline Cardiopatía congénita & $50 \%$ & $\begin{array}{l}\text { Tetralogía de Fallot } \\
\text { Defectos del septo auricular }\end{array}$ \\
\hline Gastrointestinales & $40 \%$ & $\begin{array}{l}\text { Atresia intestinal, duplicaciones, } \\
\text { hernia diafragmática congénita, pentalogía de Cantrell }\end{array}$ \\
\hline Renales & $<10 \%$ & Malrotaciones renales \\
\hline Genitourinarias & $<10 \%$ & Extrofia vesical y cloacal \\
\hline Faciales & $<10 \%$ & Labio leporino y paladar hendido \\
\hline
\end{tabular}

Adaptado de McNair y col. ${ }^{5}$

del intestino medio, lo que conlleva a su protrusión fuera de la cavidad abdominal a través del cordón y el anillo umbilical. En la décima semana el intestino delgado retorna a la cavidad abdominal, después lo hace el colon siguiendo un complejo proceso, ordenado y secuencial que incluye rotación, alargamiento, fijación y fusión de la pared abdominal. ${ }^{3,5,7}$ Aun no es claro por qué se produce el onfalocele, pero se han propuesto tres teorías: 1) alteración en la migración y el desarrollo durante la plicatura de los pliegues abdominales, 2) persistencia del tallo corporal y 3 ) defectos durante el regreso del intestino al abdomen y persistencia de este en el cordón umbilical. ${ }^{3,5}$

El diagnóstico se realiza con ecografía prenatal, herramienta valiosa que aporta información sobre el tamaño del defecto, los órganos eviscerados, permite diferenciar la gastrosquisis e indica otras anomalías asociadas. ${ }^{2}$ Tiene una sensibilidad de 60 a $75 \%$ y una especificidad de $95 \%$ de acuerdo con el tiempo de realización y el operador. ${ }^{3}$ En casos donde los hallazgos son indeterminados la resonancia magnética proporciona información adicional. ${ }^{2}$ La alfa fetoproteína se usa para tamizar defectos del tubo neural y cromosomopatías, ${ }^{3}$ ya que esta proteína se produce en el hígado fetal y el tracto gastrointestinal, se excreta en orina fetal al líquido amniótico y difunde a la circulación materna. ${ }^{5}$ En el caso del onfalocele el contacto de las membranas y los vasos sanguíneos permite que esta se secrete al líquido amniótico por lo cual la elevación de sus niveles en el suero materno guarda relación directa con defectos de la pared abdominal. ${ }^{2,3,5}$
Se recomienda llevar a término la gestación y el parto debe ser programado. En series retrospectivas no se han encontrado diferencias en la mortalidad respecto a la vía del nacimiento. ${ }^{2}$ Se prefiere la cesárea para evitar distocias, conservar la integridad de las membranas y prevenir trauma hepático y hemorragia. ${ }^{2,5} \mathrm{El}$ manejo postnatal incluye el $\mathrm{ABC}$ de la reanimación neonatal y los cuidados posreanimación, conservando el ambiente térmico óptimo para prevenir la hipotermia. ${ }^{3}$ Se deben proteger el defecto, las vísceras herniadas y disminuir el riesgo de infección. ${ }^{5}$ Es importante verificar la integridad de la membrana del saco, pues en caso de estar rotas se debe garantizar la adecuada perfusión e hidratación de las vísceras y el uso de antibióticos profilácticos. ${ }^{3}$ El paso de sonda orogastrica evita la distensión del tracto gastrointestinal.

El manejo quirúrgico consiste en el cierre primario en aquellos defectos menores de cinco centímetros. Se puede diferir cuando el cierre cause hipertensión abdominal, siempre que las membranas se encuentren integras. ${ }^{2,5}$ La técnica de Schuster se propone en casos de onfaloceles gigantes, involucra la creación de un silo "chimenea" cubriendo el defecto con una prótesis de silastic alrededor de la fascia y en forma periódica se procede a comprimir la prótesis para reducir el contenido herniado, además se suspende la bolsa en la parte superior del abdomen y por efecto de gravedad se ayuda al proceso. ${ }^{5} \mathrm{Si}$ hay contraindicación para el procedimiento quirúrgico se han propuesto manejos tópicos para epitelizar las membranas que cubren el defecto, entre ellas el uso de yodopovidona, alcohol al 
$70 \%$ y mercurio cromo al $2 \%$, los cuales se encuentran en desuso por su potencial toxicidad sistémica y efectos sobre la función tiroidea. ${ }^{8,9} \mathrm{El}$ uso de sulfadiazina de plata como agente epitelizador se ha propuesto en las últimas dos décadas, con la ventaja de disminuir la colonización por patógenos, debido a la alta tasa de infecciones que presentan estos pacientes. ${ }^{4,10}$ Existen series pequeñas que muestran éxito con el uso tópico de sulfadiazina de plata. ${ }^{4}$ Sin embargo no hay estudios sistemáticos debido a la baja frecuencia del defecto. Entre las reacciones adversas reportadas se describen las relacionadas con la toxicidad por plata, convulsiones, neuropatía periférica, elevación de transaminasas y leucopenia. Aún no se ha establecido la dosis tóxica acumulada por el manejo con sulfadiazina de plata en estos pacientes. Una vez se ha logrado la epitelización completa del saco se puede evaluar a los seis o doce meses la reparación de la hernia ventral epitelizada., Nuestro paciente fue candidato para el tratamiento médico tópico con buenos resultados, sin reporte de reacciones adversas ofreciendo una opción terapéutica segura para el paciente con onfalocele gigante.

\section{Referencias}

1. Evbuomwan I, Lakhoo K. Congenital anterior abdominal wall defects: exomphalos and gastroschisis. In: Ameh E, Bickler S, Lakhoo K, Nwomeh B, Poenaru D. Paediatric surgery: a comprehensive text for Africa. 1st ed. Seattle, WA: Global HELP Organization. 2011. p. 348-51

2. Davis A, Blumenfeld Y, Rubesova E, Abrajano C, El-Sayed Y. Dutta S, et al. Challenges of Giant Omphalocele: From Fetal Diagnosis to Follow-up. Neoreviews. 2008; 9: e338

3. Ledbetter DJ. Gastroschisis and omphalocele. Surg Clin North Am. 2006; 86(2): 249-60

4. Ein SH, Langer JC. Delayed management of giant omphalocele using silver sulfadiazine cream: an 18-year experience. J Pediatr Surg. 2012;47(3):494-500

5. McNair C, Hawes J, Urquhart H. Caring for the newborn with an omphalocele. Neonatal Netw. 2006; 25(5):319-27

6. Ledbetter DJ. Congenital abdominal wall defects and reconstruction in pediatric surgery: gastroschisis and omphalocele. Surg Clin North Am. 2012; 92(3):713-27

7. Sadler TW. Aparatos respiratorio y digestivo. En: Sadler TW. Langman fundamentos de embriología médica con orientación clínica. Buenos Aires: Médica Panamericana; 2006. p. 59-70

8. Abramson L, Luck S, Arensman R. Omphalocele. In: Mattei P, editor. Surgical directives: pediatric surgery. Philadelphia: Lippincott Williams \& Wilkins; 2003. p. $517-20$

9. Whitehouse JS, Gourlay DM, Masonbrink AR, Aiken JJ, Calkins CM, Sato TT, et al. Conservative management of giant omphalocele with topical povidone-iodine and its effect on thyroid function. J Pediatr Surg. 2010;45(6):1192-7

10. Almond S, Reyna R, Barganski N, Emran MA. Nonoperative management of a giant omphalocele using a silver impregnated hydrofiber dressing: a case report. J Pediatr Surg. 2010; 45(7):1546-9 